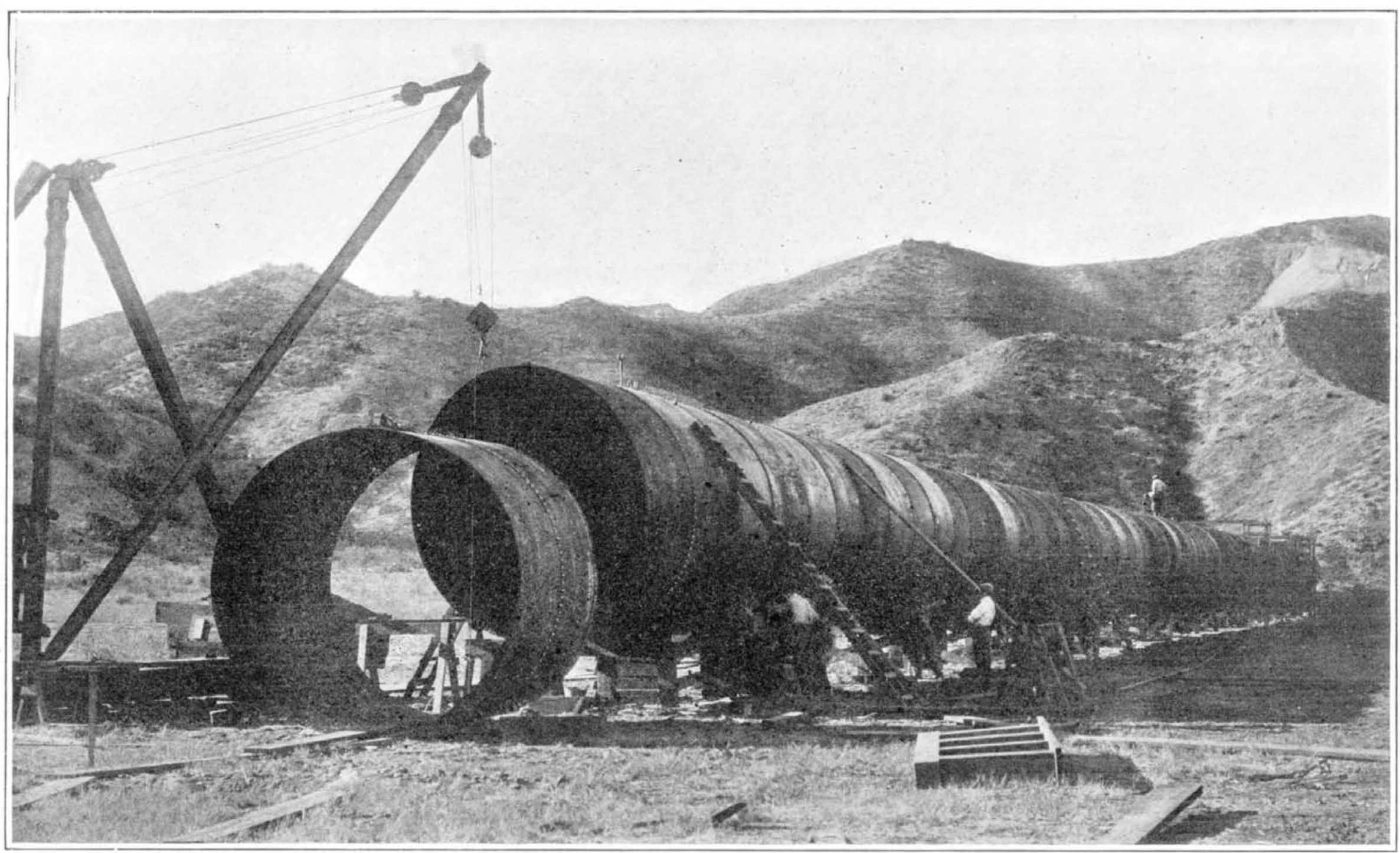

The Deadman siphon in process of erection.

\title{
An Aqueduct Two Hundred and Forty Miles Long
}

How Steel and Concrete Siphons will Supply Los Angeles with Water

By Burt A. Heinly

S IMUltaneOUSLY but on opposite sides of the $S_{\text {continent, water works projects are under way such }}$ as have no parallel in history: The Catskill Mountain Aqueduct, ninety-two miles in length, which is to serve the metropolis of New York, and the Los Angeles Aqueduct, 240 miles long, to supply the city of Los Angeles. Exclusive of the tunnel work of which there is fortyseven miles in the Los Angeles Aqueduct, probably the most interesting feature of this great enterprise by which the waters of the eastern face of the Sierra are to be caried around the western rim of the Mojave Desert, beneath the Sierra Madre Range and into the San Fernando Valley, north of the city, is the construction of twenty-two inverted steel siphons. It is by this means that the flow of the aqueduct will be borne across deep canyons and broad valleys. These huge steel pipes, with the exception of one of large diameter at Niagara Falls and a steel main imbedded in conat Niagara Falls and a steel main imbedded in crete near Madrid, Spain, are, so far as the write knows, the largest in existence. They range in length from 611 to 15,596 feet, and in diameter from 8 feet 6 inches to 11 feet. The designs call for a minimum capacity of 430 second feet. Varying with the pressure, the thickness of the steel ranges from one-fourth inch to one and one-eighth inches.

Where the depressions are shallow and the head is light, as in the case of Whitney and Ellsmore canyons, siphons constructed of concrete, heavily reinforced with steel, are used-this because of the cheaper cost.
The aggregate length of the steel siphons of the Los Angeles Aqueduct is 49,576 feet, which, with the concrete siphon approaches and siphons composed entirely of reinforced concrete, brings the total footage of this class of construction to 63,585 feet.

The maximum head varies greatly, the lowest being 50 feet while that of the siphon crossing Jawbone Canyon amounts to 850 feet. This siphon, for which the steel is now being delivered, will have a total length of 8,095.51 feet the pipe ranging in diameter from 10 feet to 7 feet 6 inches and the thickness of steel from a quarter of an inch to one and one eighth inches. The aggregate tonnage of steel amounts to 14,500 tons. Loaded 40,000 pounds to the car, it requires 700 cars or 35 trains of 20 cars each to transport the material from Eastern steel factories to the various destinations along the Mojave Desert

The longest siphon is that by which the waters of the aqueduct are borne across the upper reaches of the Antelope Valley, an arm of the Mojave desert lying along the northern base of the Sierra Madre range. This siphon at its northern end consists of a concrete pipe 10 feet in diameter, which sustains a maximum head of 75 feet, 15,596 feet of steel pipe 10 feet in diameter with plates one quarter to three eighths inches in thickness, constructed for a head of 200 feet, and 3,414 feet of 10 -foot concrete pipe at the southern end for a head of 75 feet. All this work is being done 35 miles from the nearest railroad.
At the lowest point in the siphon, two 24-inch doubledisk Rensselaer gate valves were installed. These valves placed over the lowermost pier to insure stability when open, obviously are used for cleaning purposes; but their most important function at first sight may not be apparent. For long distances the aqueduct follows the contour of the steep mountain side at an elevation ranging from 800 to 1,200 feet above the fioor of the desert. Damage to the aqueduct from slides or other causes would be largely increased by the after steep gradient. These gates will therefore serve, in case of accident, to divert the fiow of the aqueduct into the natural channels of the canyons where the hydraulic force will be without disastrous consequences. The Nine Mile siphon exclusive of the piers was completed at a cost of $\$ 18.47$ per linear foot This is at could have been done by contract. The work on the siphon across Soledad Canyon is being done somewhat cheaper than this. Here two sections are riveted together and the 12-foot length is then hoisted by a giant crane into its proper position in the siphon.

The completion of the aqueduct, unless unforeseen financial delays should intervene, will be accomplished during the early months of the year 1913 at a total cost of $\$ 24,500,000$, and it is expected that the siphon work will be in place by November of this year.

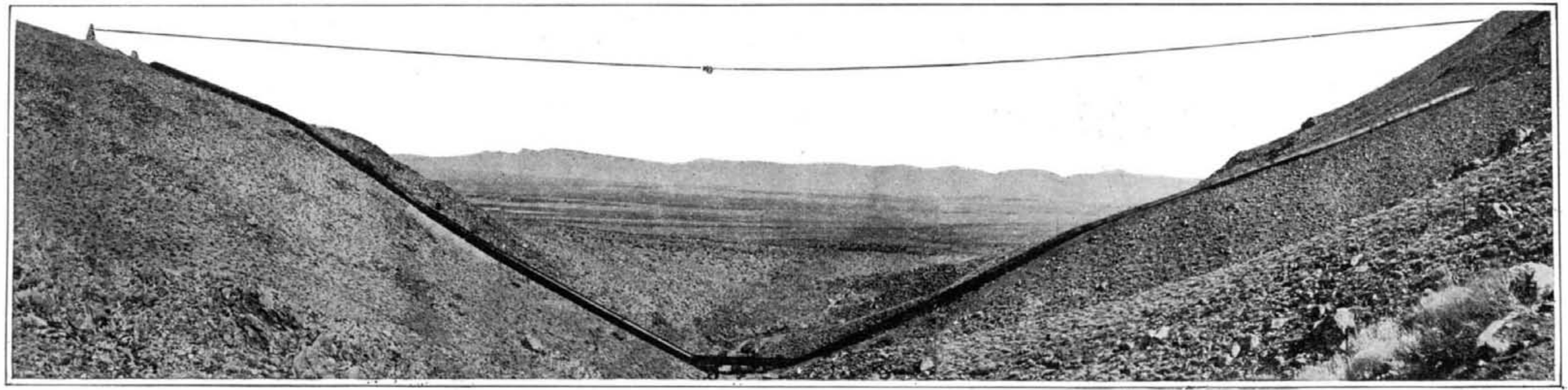

One of the huge steel siphons of the Los Angeles aqueduct. 